parents whose children are being educated? What rights do individual teachers, school districts or states have to impose particular values, whether secular or traditionally religious, on all children? None of these questions seems especially related to natural science, although it remains interesting why they have become so. In any case, creation-scientists and their ilk, despite their extremism and many scientific foibles, are drawing attention to some notable yet unresolved questions related to attaining genuine pluralism in American life and education.

George M. Marsden is Professor of History at Calvin College, Grand Rapids, Michigan, and author of Fundamentalism and American Culture (Oxford University Press, 1980).

\section{Gnawing doubts}

\section{Bernard Wood}

Teeth: Form, Function, and Evolution. Edited by Björn Kurtén.

Columbia University Press: 1982. Pp.383. $\$ 50$ (US), \$65 (elsewhere).

IN THE summer of 1979, fifty scientists with diverse interests in teeth gathered in Finland for the Fifth International Symposium on Dental Morphology. This volume contains the texts of the papers read at the meeting. The contributions cover a wide variety of topics and are themselves variable in quality.

The 25 papers have been classified under one of four topic headings - Ontogeny; Structure, Shape and Function; Populations; and finally Evolution - but the categorization is sometimes confusing. The editor is to be commended for preparing a volume index, but it would have been useful if he had insisted on a more uniform format for the papers. Some have an abstract and a conclusions section; regrettably others have neither.

The first section on ontogeny (containing seven papers) is perhaps the strongest. Three (Kollar, Lumsden and Savara et al.) are essentially presentations of research methods, but they nonetheless represent important advances in this field of research. Two others, by Butler and Moss, are more reflective and Butler's contribution is a particularly stimulating essay on the development of tooth patterns.

\section{Plants under threat}

A revised version of the British Red Data Book Vascular Plants has been issued by the Royal Society for Nature Conservation, supplanting the previous edition published in 1977. As well as details of each endangered species, the book includes brief accounts of how the information is compiled and of pertinent legal and scientific issues. Copies are available from RSNC, The Green, Nettleham, Lincoln, price $£ 7$ post paid.
In the next section two papers stand out: one for its strengths and the other for its weaknesses. Schwartz presents a critical examination of the problems of heterodonty and homology. He asks whether teeth are homologous, or whether it is the sites (e.g. the premaxilla) which are homologous with different teeth coming to rest in different places in different animals. He comes down in favour of the latter interpretation, and presents a developmental model to explain the differentiation of not only the basic tooth types, but also the variation within each type. Gantt's contribution, by contrast, is poorly edited and made more confusing by the lack of any labelling on an important figure.

The problem of dealing with the effects of attrition is one which particularly bedevils the work of hominid palaeontologists and the results presented in van Reenen's paper will be useful when evaluating the significance of differences in tooth size between presumed hominid taxa. However, the paper would have been more useful if it had included a table giving the percentage reduction in tooth size due to attrition for individual teeth.

Two papers in the section dealing with populations illustrate the extra difficulties scientists make for themselves, and others, when they are careless in their definition of morphological variants. Both Axelsson and Kirveskari, and Scott and Dahlberg, include an assessment of the incidence of the $\mathrm{C} 6$ in their studies, but by choosing to define it differently they render their results incompatible.

The final section, on evolution, contains only four papers, and one of these is really about ontogeny. Rensberger's contribution deals with Miocene aplodontid rodents, but is commendably functionally orientated and one wonders why it is not in the second section along with a similar paper by Fortelius dealing with rhinoceroses. The last paper, by Patricia Smith, has the seductive but, as it turns out, misleading title of "Dental Reduction: Selec tion or Drift". In the abstract she implies that in four continents there are examples of neighbouring populations in which tooth size can be related to diet, yet the only detailed evidence she cites or quotes for this comes from Australia. The promised discussion of the rival merits of selection and drift never materializes.

Interest in teeth is undergoing a modest revival and the increasing dialogue between developmental biologists and palaeontologists is particularly promising, but this volume conveys little of this excitement. There is evidence from at least one of the papers that the meeting provided the opportunity for fruitful discussion, but even so a successful meeting does not always result in the publication of a useful set of proceedings. Such, sadly, is the case with this book

Bernard Wood is Professor of Anatomy at The Middlesex Hospital Medical School, London.

\section{Descent and dissent}

Barry Cox

Archetypes and Ancestors: Palaeontology in Victorian London 1850-1875.

By Adrian Desmond.

Blond and Briggs: 1982. Pp.287. £15.95.

MosT scientists are uninterested in the history of their profession, perhaps tending to see earlier science as at best merely a collection of inadequate halftruths. Yet ideas, like animals, are adapted to their environment, now as then. The views of society and of current science constrain our choice of research topic and of the currently-respectable range of theories that we may prefer. The development of these theories is also often partly moulded, even perverted, by the theories of the other scientists with whom we interact.

But, if we try to learn History's lessons, we have to beware of simply accepting the victor's tales of the conflicts, which merely perpetuate their partisan view, turning the losers into mere reactionaries and the victors into selfless bringers of new light. Adrian Desmond has tried to set the record straight in his account of the battle that was fought, largely in the laboratories and lecture halls of London, over Darwin's new theory of evolution by natural selection. He has clearly shown the social, philosophical and personal differences which underlay the prolonged debate, in which Owen and Huxley were the leading protagonists.

The conservatism and obduracy of Owen and the Establishment have long been clearly highlighted. Desmond's contribution is to redress the balance by showing the ambitiousness, intolerance and inconsistency of Huxley and his supporters. He shows that they identified themselves with the increasingly powerful bourgeoisie, who saw the idea of evolution as the sharp edge of an instrument of social change. Their aim was the replacement of the Old Guard at the levers of power - not merely in general terms in Society as a whole, but also in personal advancement within science by capturing the prestigious and influential positions within the universities, museums and scientific societies.

Perhaps the most interesting result is the extent to which Huxley reacted to the opposition's theories, rather than singlemindedly merely weaving all the available evidence into the garment designed by Darwin. For example, Owen invented the Archetypes of the book's title as abstract blueprints, from which each of the successive fossil forms of each major group had been directly produced by gradually increasing degrees of divine modification. One might have expected Huxley just to re-interpret the data and to use that same 